\title{
Epidemiology of Vascular Neck Injury in Polytrauma Patients in Emergency Hospital Mansoura University, Egypt
}

\author{
Ahmed Magdy Saleh ${ }^{1}$, Hosam Roshdy Zaher ${ }^{2}$, Mohamed El-Said Ibrahim ${ }^{3}$, Samir Mohamed Attia ${ }^{2}$ \\ Departments of ${ }^{1}$ Emergency Medicine, ${ }^{2}$ Vascular Surgery, ${ }^{3}$ Critical Care Medicine, \\ Faculty of Medicine, Mansoura University, Dakahlia, Egypt \\ *Corresponding author: Ahmed Magdy Saleh, Mobile: (+20) 01024240079, Email: ahmed.mg.sa@ @otmail.com
}

\begin{abstract}
Background: Trauma is considered to be the second most common cause of disability. Injuries to the neck can have significant morbidity and mortality that demand immediate attention and intervention. The most common clinical presentations for patients who reach trauma centers alive are shock, active bleeding, hematoma, and neurologic deficit.

Objective: To determine the epidemiology of vascular neck injuries to patients admitted to Emergency Hospital, Mansoura University.

Materials and Methods: This study was conducted on 96 cases admitted to Emergency Hospital, Mansoura University suffering from Neck Vascular Injuries. Assessment includes ABCDE approach, AMPLE history taking, full clinical examination, and radiological investigations that involve FAS, multislice CT brain, Duplex U/S, and CTA (computed tomographic angiography) in selective cases.

Results: shock was the main presenting symptom. Neck zone II was the most commonly affected in $41(42.7 \%)$ of cases. Operative treatment was performed in $68(70.8 \%)$ cases while Conservative treatment was performed in 28 (29.2\%) cases. AS regards Incidence of mortality, 44 (45.8\%) of cases died compared with $52(54.2 \%)$ of cases who were Survived.

Conclusion: Neck injuries were relatively uncommon, found in $2.5 \%$ of all TQIP observations. Penetrating trauma was the predominant mode of trauma among the studied cases. Shock was considered the commonest presenting symptom followed by airway compromise. The main management was operative treatment.
\end{abstract}

Keywords: Trauma, Neck, Operative, Shock, Penetrating.

\section{INTRODUCTION}

Trauma itself is a pandemic that is projected to be the second most common cause of disabilityadjusted life years lost within the next thirteen years (1). Trauma accounts for about 16000 deaths a day worldwide ${ }^{(2)}$. The neck is a complex anatomical region because, in a small space, there are numerous critical aerodigestive, neurological, and vascular structures ${ }^{(3)}$.

Injuries to the neck can have significant morbidity and mortality that demand immediate attention and intervention ${ }^{(4)}$. This is related not only to massive bleeding and cerebral ischemia due to embolization or thrombotic occlusion associated with the vascular injury but also to secondary damage to the aerodigestive tract (e.g., airway compression from a large expanding hematoma). The most common mechanism is penetrating injuries, but the incidence of blunt vascular trauma is probably underestimated because related symptoms are often vague and not recognized or absent ${ }^{(5)}$.

A quick diagnosis and prompt treatment are mandatory to reduce the mortality and morbidity of these complex injuries ${ }^{\left({ }^{6}\right)}$. The most common clinical presentations for patients who reach trauma centers alive are shock, active bleeding, hematoma, neurologic deficit, and bruit. Once diagnosed, the patient's clinical condition guides treatment ${ }^{(7)}$.
The management of neck injuries has changed dramatically over the last 30 years with modern imaging techniques, from a mandatory exploration of all wounds that penetrated the platysma to an increasingly selective approach ${ }^{(8)}$. Technological advances in interventional radiology and endovascular procedures allow the identification and management of potentially life-threatening injuries while saving many patients from surgery ${ }^{(3)}$.

The current study aimed to determine the epidemiology of vascular neck injuries to patients admitted to the Emergency Hospital, Mansoura University.

\section{PATIENTS AND METHODS}

This was retrospective (from Jan 2015 to Jan 2020) and prospective (from Feb 2020 to Jan 2021) to traumatic patients admitted to Emergency Hospital, Mansoura University suffering from Neck Vascular Injuries. Emergency Hospital Mansoura University is a level one trauma center with about 250,000 visits and 25,000 trauma cases per year.

Ethical Considerations:

An approval of the study was obtained from Mansoura University academic and ethical committee. Every patient signed an informed written consent for acceptance of the operation. 
Inclusion criteria: Patients with a blunt or penetrating neck injury and both genders.

Exclusion criteria: At least one of the following conditions: Patients with superficial neck wounds and Patients who died before admission.

\section{All cases are subjected to:}

1. Resuscitation of the patient: Airway maintenance $\&$ cervical spine immobilization, Breathing and ventilation, Circulation, and control of hemorrhage, Disability: neurological status and Glasgow coma scale (GCS).and Exposure / environmental control.

2. History taking by AMPLE history: Allergies. Medication currently used. Past illnesses / Pregnancy, Last meal. Events / Environment related to the injury.

3. Clinical Examination and 2ry survey: Full clinical examination of all body.

4. Radiological investigations: FAST (Focused Assessment with Sonography for Trauma), X-ray (chest, pelvis, lumbosacral spine and cervical spine), Multislice CT brain. If suspected vascular neck injuries: Duplex U/S to the neck and CTA (computed tomographic angiography) in selective cases.

5. Outcome was estimated by hospital length of stay, intensive care unit length of stay, and morbidity as well as mortality.

\section{Statistical analysis}

Data were analyzed using the Statistical Package of Social Science (SPSS) program for Windows (Standard version 21). The normality of data was first tested with a one-sample KolmogorovSmirnov test. Qualitative data were described using number and percent. Association between categorical variables was tested using the Chi-square test. Continuous variables were presented as mean \pm SD (standard deviation) for parametric data. The two groups were compared with the Student t-test while ANOVA test was used to compare more than 2 means. Pearson correlation was used to correlate continuous parametric data. $\mathrm{P}$ value $<0.05$ was considered statistically significant.

\section{RESULTS}

The demographic data of the study cases $(n=96)$ revealed that the mean and median ages of the studied cases were 34.84 and 32.5 years, respectively. The study included 9 (9.38\%) females and 87 $(90.62 \%)$ males Table (1).

Table (1): Demographic data of the study cases.

\begin{tabular}{|l|l|c|}
\hline \multicolumn{2}{|l|}{ Items } & \multicolumn{1}{c|}{$\begin{array}{c}\text { Study cases }(\mathbf{n}= \\
\text { 96) }\end{array}$} \\
\hline \begin{tabular}{l|l|} 
Age \\
(years)
\end{tabular} & Mean \pm SD & $34.84 \pm 12.29$ \\
\cline { 2 - 3 } & Median (min-max) & $32.5(19-60)$ \\
\hline Sex & $9(9.38 \%)$ \\
\hline Females & $87(90.62 \%)$ \\
\hline Males
\end{tabular}

Continuous data expressed as mean \pm SD and median (range)
Categorical data expressed as Number (\%)

Mode of trauma (MOT) is shown as following: Penetrating trauma was demonstrated in 62 (64.6\%) of cases, blunt trauma was demonstrated in 26 (27.1\%) of cases while external neck pressure was demonstrated in $8(8.3 \%)$ of cases. As regards the pattern of penetrating trauma, the gunshot was detected in 21 (33.9\%) cases, stab was detected in 30 (48.4\%) cases while falling on a sharp object was detected in $11(17.7 \%)$ cases Table (2).

Table (2): Mode of trauma (MOT) in the study cases.

\begin{tabular}{|l|c|}
\hline Items & Study cases $(\mathbf{n = 9 6 )}$ \\
\hline Mode of trauma (MOT) \\
\hline Penetrating trauma & $62(64.6 \%)$ \\
\hline Gunshot & $21(33.9 \%)$ \\
\hline Stab & $30(48.4 \%)$ \\
\hline $\begin{array}{l}\text { Falling on a sharp } \\
\text { object }\end{array}$ & $11(17.7 \%)$ \\
\hline Blunt trauma & $26(27.1 \%)$ \\
\hline External neck pressure & $8(8.3 \%)$ \\
\hline
\end{tabular}

Categorical data expressed as Number (\%)

As regards the presenting symptoms/signs, Shock was present in $65(67.7 \%)$ of cases, pulsatile bleeding was present in $13(13.5 \%)$ of cases, expanding hematoma was present in $8(8.3 \%)$ of cases, audible bruit or palpable thrill was present in 17 (17.7\%) of cases, airway compromise was present in $24(25 \%)$ of cases, hoarseness was present in 11 $(11.5 \%)$ of cases and signs of stroke or cerebral ischemia were present in 7 (7.3\%) of cases Table (3).

Table (3): Analysis of the presenting symptoms/signs in the study cases.

\begin{tabular}{|l|c|}
\hline Items & Study cases $(\mathbf{n = ~ 9 6 )}$ \\
\hline Shock & $65(67.7 \%)$ \\
\hline Pulsatile bleeding & $13(13.5 \%)$ \\
\hline Expanding hematoma & $8(8.3 \%)$ \\
\hline $\begin{array}{l}\text { Audible bruit or } \\
\text { palpable thrill }\end{array}$ & $17(17.7 \%)$ \\
\hline Airway compromise & $24(25 \%)$ \\
\hline Hoarseness & $11(11.5 \%)$ \\
\hline $\begin{array}{l}\text { Signs of stroke or } \\
\text { cerebral ischemia }\end{array}$ & $7(7.3 \%)$ \\
\hline
\end{tabular}

Categorical data expressed as Number (\%)

Regarding the affected neck region, Neck zone II was the most commonly affected in $41(42.7 \%)$ of cases followed by Neck zone 1 in 29 (30.2\%) of cases while Neck zone III was the least frequently involved in $26(27.1 \%)$ of cases Table (4). 
Table (4): Analysis of the affected neck region in the study cases.

\begin{tabular}{|l|c|}
\hline Items & Study cases (n= 96) \\
\hline Neck zone 1 & $29(30.2 \%)$ \\
\hline Neck zone II & $41(42.7 \%)$ \\
\hline Neck zone III & $26(27.1 \%)$ \\
\hline
\end{tabular}

Categorical data expressed as Number (\%)

Considering CT angiography, the common carotid artery was involved in $9(13.4 \%)$ of cases, the internal carotid artery was involved in 14 (20.9\%), External carotid artery was involved in $21(31.3 \%)$ of cases, internal jugular vein was present in $13(19.4 \%)$ of cases and external jugular vein was involved in 17 (25.4\%) of cases Table (5).

Table (5): Analysis of the findings of CT angiography in the study cases.

\begin{tabular}{|l|c|}
\hline Items & $\begin{array}{c}\text { Study cases (Performed } \\
\text { CT Angio) } \mathbf{( n = 6 7 )}\end{array}$ \\
\hline Common carotid artery & $9(13.4 \%)$ \\
\hline Internal carotid artery & $14(20.9 \%)$ \\
\hline External carotid artery & $21(31.3 \%)$ \\
\hline Internal jugular vein & $13(19.4 \%)$ \\
\hline External jugular vein & $17(25.4 \%)$ \\
\hline
\end{tabular}

Categorical data expressed as Number (\%)

Operative treatment was performed in 68 $(70.8 \%)$ cases while conservative treatment was performed in 28 (29.2\%) cases Table (6).

Table (6): Analysis of management strategy of the study cases.

\begin{tabular}{|l|c|}
\hline Site of admission & Study cases $(\mathbf{n}=\mathbf{9 6})$ \\
\hline Operative treatment & $68(70.8 \%)$ \\
\hline Conservative treatment & $28(29.2 \%)$ \\
\hline
\end{tabular}

AS regards the incidence of mortality, 44 (45.8\%) cases died compared with $52(54.2 \%)$ cases who were survived Table (7):

Table (7): Incidence of mortality of the study cases.

\begin{tabular}{|l|c|}
\hline \multicolumn{1}{|c|}{ Survival } & Study cases $(\mathbf{n}=96)$ \\
\hline Died & $44(45.8 \%)$ \\
\hline Survived & $52(54.2 \%)$ \\
\hline
\end{tabular}

\section{DISCUSSION}

The neck is a complex anatomical region because, in a small space, there are numerous critical aerodigestive, neurological, and vascular structures ${ }^{(3)}$.

Moreover, the current study showed the Mode of trauma (MOT) in the cases. Penetrating trauma was demonstrated in $62(64.6 \%)$ of cases, blunt trauma was demonstrated in $26(27.1 \%)$ of cases while external neck pressure was demonstrated in $8(8.3 \%)$ of cases. As regards the pattern of penetrating trauma, a gunshot was detected in 21 (33.9\%) cases, stab was detected in $30(48.4 \%)$ cases while Falling on a sharp object was detected in $11(17.7 \%)$ cases.

On the other hand, Perkins et al. ${ }^{(9)}$ studied epidemiology, management strategies, and outcomes from vascular trauma in the United Kingdom. It was found that penetrating trauma accounted for a significantly higher proportion of vascular trauma admissions than general trauma admissions (53\% vs. $24 \%, \mathrm{p}<0.0001)$. Stab wounds were the most frequent cause of vascular injuries and were five times more common than gunshot wounds (GSW). Road traffic collisions (RTC) and falls from height were the predominant cause of blunt vascular injuries.

Regarding the presenting symptoms/signs in the cases included in the study, shock was present in 65 $(67.7 \%)$ cases, pulsatile bleeding was present in 13 $(13.5 \%)$ cases, expanding hematoma was present in 8 $(8.3 \%)$ cases, audible bruit or palpable thrill was present in 17 (17.7\%) cases, airway compromise was present in $24(25 \%)$ cases, hoarseness was present in $11(11.5 \%)$ cases and Signs of stroke or cerebral ischemia were present in 7 (7.3\%) cases.

Rathlev et al. ${ }^{(10)}$ concluded that clinical symptoms range from patients who have no symptoms to those who have life-threatening airway compromise or profound shock. Penetrating injuries to the airway may present with dyspnea, hoarseness, and cough. Conversely, progressive airway obstruction from an external source, such as an expanding hematoma, often presents with abnormal respiratory patterns, stridor, dysphonia, tachypnea, or cyanosis.

The affected neck region in the cases was demonstrated in the current study. Neck zone II was the most commonly affected in $41(42.7 \%)$ cases followed by Neck zone 1 in $29(30.2 \%)$ cases while Neck zone III was the least frequently involved in 26 (27.1\%) cases.

As regard analysis of the findings of CT angiography in the two study groups, there was no statistically significant difference between penetrating and blunt vascular trauma in the common carotid artery, internal carotid artery, external carotid artery, internal jugular vein, or External jugular vein $(\mathrm{P}=0.840,0.965,0.417,0.362$ and 0.325 respectively).

Perkins et al. (9) concluded that the predominant investigation for vascular injuries was a contrast Computerized Tomography (CT) scan. The proportion of patients having a contrast CT increased annually, peaking at $96 \%$ of blunt vascular and $40 \%$ of penetrating vascular trauma in 2010. Diagnostic angiograms were utilized in $6 \%$ of patients and the majority were on-table procedures.

In harmony with these results, a retrospective study was performed by Irish $\boldsymbol{e t}$ al. ${ }^{(11)}$ on all 85 patients admitted to The Toronto Hospital with a 
diagnosis of blunt or penetrating injury, or both, to the neck. The study showed that Neck zone II was the most commonly affected in $82 \%$ of cases followed by Neck zone III in $5 \%$ of cases while Neck zone 1was the least frequently involved in $2 \%$ of cases.

Additionally, the management strategy of the included cases was shown in the study. Operative treatment was performed in $68(70.8 \%)$ cases while Conservative treatment was performed in 28 (29.2\%) cases. Analysis of the site and duration of admission of cases included in the study showed that $(78.2 \%)$ of cases were admitted to ICU, while $21(21.8 \%)$ were admitted to the ward and $59(61.5 \%)$ of cases were admitted $<7$ Days, while $37(38.5 \%)$ of cases were admitted $\geq 7$ Days.

Conversely, Harris et al. ${ }^{(12)}$ performed a cohort study comparing incidence and management protocol of penetrating neck trauma in London. Twenty-three $(74 \%)$ cases were managed conservetly with a median LOS of $<1$ day. None of these cases required surgery at later date and there were no mortalities. Eight (26\%) cases were managed surgically with a median LOS of 4.5 days.

Regarding the incidence of mortality of cases included in the study, $44(45.8 \%)$ of cases died compared with $52(54.2 \%)$ of cases who were Survived. Also, Perkins et al. ${ }^{\left({ }^{9}\right)}$, highlighted the high morbidity and mortality associated with vascular trauma. The overall mortality in that series was $18 \%$, and compares favorably to that observed by other Major Trauma Centers with similar mechanisms and distributions of vascular injuries $(24 \%-26 \%)^{(13)}$.

\section{CONCLUSION}

Neck injuries were relatively uncommon, found in 2.5\% of all TQIP observations from 2012 to 2016. Penetrating trauma was the predominant mode of trauma among the studied cases. Shock was considered the commonest presenting symptom followed by airway compromise.

The main management was operative treatment in $70.8 \%$ of cases while Conservative treatment was decided for $29.2 \%$ of cases. Death occurred more in cases with penetrating trauma.
1. Chandran A, Hyder A, Peek-Asa C (2010): The global burden of unintentional injuries and an agenda for progress. Epidemiologic Reviews, 32(1): 110-120.

2. Lecky F, Bouamra O, Woodford M et al. (2010): Epidemiology of polytrauma. In Damage control management in the polytrauma patient. Springer. Pp. 1324.

3. Pirrelli S, Quaretti P, Moramarco L et al. (2019): Vascular Injuries of the Neck. In Operative Techniques and Recent Advances in Acute Care and Emergency Surgery. Springer. Pp. 229-252.

4. Burgess C, Dale O, Almeyda R et al. (2012): An evidence-based review of the assessment and management of penetrating neck trauma. Clinical Otolaryngology, 37(1): 44-52.

5. Wahlberg E, Goldstone J (2017): Emergency vascular surgery: a practical guide: Springer. Pp. 193-207. https://www.springer.com/gp/book/9783642079382

6. Daou B, Alkhalili K, Chalouhi N et al. (2017): Epidemiology, pathophysiology, and treatment of the traumatic cervical vascular injury. Seminars in Spine Surgery, 29(1). https://www.researchgate.net/ publication/308754940_Epidemiology_pathophysiolog y_treatment_of_traumatic_cervical_vascular_injury

7. Asensio J, Verde J, Ünlü A et al. (2011): Vascular injuries of the neck. In Head, Thoracic, Abdominal, and Vascular Injuries. Springer. Pp. 381-392.

8. Shiroff A, Gale S, Martin N et al. (2013): Penetrating neck trauma: a review of management strategies and discussion of the 'No Zone'approach. The American Surgeon, 79(1): 23-29.

9. Perkins Z, De'Ath H, Aylwin C et al. (2012): Epidemiology and outcome of vascular trauma at a British Major Trauma Centre. European Journal of Vascular and Endovascular Surgery, 44(2): 203-209.

10. Rathlev N, Medzon R, Bracken M (2007): Evaluation and management of neck trauma. Emergency Medicine Clinics of North America, 25(3): 679-694.

11. Irish J, Hekkenberg R, Gullane $P$ et al. (1997): Penetrating and blunt neck trauma: a 10-year review of a Canadian experience. Canadian Journal of Surgery, 40(1): 33-36.

12. Harris R, Olding C, Lacey $\mathrm{C}$ et al. (2012): Changing incidence and management of penetrating neck injuries in the South East London trauma center. The Annals of The Royal College of Surgeons of England, 94(4): 235239.

13. Loh S, Rockman C, Chung C et al. (2011): Existing trauma and critical care scoring systems underestimate mortality among vascular trauma patients. Journal of Vascular Surgery, 53(2): 359-366.

\section{REFERENCES}

